Khan, Akhter H. 1977

K.C.. Krish B. 1990
Ten Decades of Rural DevelopmentLessons from India. East Lansing: MSU.

Community Development - The Nepalese Context. Kathmandu: Society for Community Development Professionals.

$\hbar$

\section{National Integration In Nepal}

- Dr. Ganesh Gurung*

- Dr. Bishnu Bhandari

\section{Concept and Definition:}

National integration is an emotional attachment to nation (Etzimi, 1965); a process as well as an end product (Angel, 1941); a condition achievable by a nation (Aberle and Fordon as quoted in Doshi, 1978, and 1989); a condition and process (Ghurye, 1968; and Cohon \& Middleton as quoted in Doshi, 1978). Ghurye emphasizes that it consists of two elements: political integration and social integration. All these above definitions suggest that integration is a drawing together of those elements into something more cohesive with the parts linked more closely together co-existence. It is through this process that people develop a deep sense of we-feeling and belongingness and thereby a feeling of national loyality. Through this process, it is possible to maintain a harmonious and lively relationship between the various structural components of

*Lecturer and Reader respectives at Tribhuvan University would like to thank their colleagues for their comments and suggestions. 
society, where so that people feel themselves to be part of a comprehensive and harmonious social life.

Cohen and Middleton (Doshi, 1978) have substituted the term integration by term incorporation. They have explained it in terms of condition and process. As a process they mean continuous interaction of diversed groups, ethnic groups or individuals in a congenial situation. And as a condition, they have used the notion of pluralism. in which they have explicitly explained that the degree of incorporation would be higher (or greater) in a place where the boundary (socio-cultural, political, economic or sociological) would be at a minimum.

Gardon, who views it as a process has attempted to look at it at two levels: the community integration level and the pluralistic integration level. Integration, in reality, is the conglomeration of people from different walks of life, where they can share and interact with each other continuously without any obstacles, regardless of their stratified position in the society. In an integrated situation, they develop the sense of "we-feeling" and disown possibilities of conflict and tension. About the importance of integration. Roy (1989: 19) states.

... integration presupposes the elimination of barriers in the primary group relations and community life of the various ethnic groups of the nation. It involves easy and fluid mixture of people of different social, religious and nationality backgrounds in various walks of life. like social cliques, families, organizations and intimate friendship".

Integration prevails in those societies, where tensions and conflicts do not prevail. It is both a process as well as an end product. Thus it can be said that integration is the main point in the society to reduce both tension and conflict. The question arises around what the societies should be integrated. In this Angel asserts that the "Common Values and Welfare" is the key thing to achieve integration in the society.
Ghurya, an Indian scholar, has classified the concept of integration. Etzione (1965) stresses that national integration means an emotional condition, which includes the concept of nation as well. It is a self-sufficient integrative mechanism (the maintenance of its existerice and form is provided for by its own processes and is not dependent upon those of external systems or member units and the notion of integration of the nation-unit is its ability "to maintain itself in the face of internal and external challenges". He has used the term unification to mean the process aspect of integration.

Nihan Ranjan Roy (as quoted in Doshi, 1978: 53) advocates that integration means a kind of participation by all group in the mainstream, namely.

(i) Integration into a common whole, where all diverse culture, population, geographical regions would be brought together,

(ii) integration into a common productive organization; and

(iii) integration into a secular and democratic set up provided by the constitution".

Lewis has said that "a single common language" is the primary force of integrating the heterogeneous societies into a single whole. He takes it as a process.

As regards the integration process of an individual, Roy $(1989: 2)$ states;

"Integration, as a subjective and individual process, involves attitudinal changes and the removal of fears, hatreds, suspicions, sterotypes and superstitions. Intergration involves problems of personal choice, personal readiness, and personal stability. Its achievement necessarily requires a longer period of time. It can't come about over night. It requires education and deals poignantly with the problems of changing men's hearts and minds".

Hark Gurung in his article Socio-economic Dimension of National Integration asserts: 
-National integration is a political idea and an ideal. It implies a national state where citizens have full right without any form of segregation". He further makes distinction of two kind of integration socio-cultural dimension and economic dimension.

Some argue that national integration comprises of state building and nation building. The former occurs at the time the political elite create new structures and organizations aimed at penetrating the society in order to regulate behaviour in it and draw a larger volume of resources from it, whereas the latter focuses on the cultural aspects of political development. It refers to the process whereby people transfer their committments and loyality from -smaller tribes, village, small communities to the larger central political system.

\section{Theoretical Framework:}

A nation can't survive, even a trivial crisis without some degree of integration. Auguste Comte, the father of sociology, expresses his opinion that consensus universalis is the foundation of solidarity or cohesion, which is used to analyze social order of coexistence (social statis) and social progress (social dynamics) in any society.

Durkheim employs the concept of social solidarity to analyze the society namely (1) mechanical solidarity and (2) organic solidarity. It is through these concepts the different components of society are bound together to maintain social unity and cohesion.

Talcott Persons suggests two theories of social integration. One is the theory of normative integration and the other is the theory of functional integration. Normative integration is based on common values shared by a population. In order to preserve these values and attain common goals, organizations are infused with these values and operate in accordance with accepted norms.
Functional integration is based on division of laboup among a number of social actors.

Employing the concept of "The Norms of Reciprocity". Gouldner opines that social actors are obliged to return benefits to those from whom they have previously received benefits. The exchange relationship provides minimal ground for confidence and promote a willingness to initiate action. It is universal; it provides a potential foundation for complementary elationship; and it is a process of creating unified social prganization.

According to Merton, manifest functions contribute to the adjustment of the system which are intended or recognized by participants in the system".

Landeckar argues that integration is not unidimensional concept. It is rather a multi-dimensional one. Because of its multi-dimensionality, it has been divided into four types of integration cultural integration (consistency among cultural stanlards), normative integration (the society's values are institutionalized in structural elements of the social system), communicative integration (use of mass media in achieving consensus) and functional integration (mutual interdependence among he units of a system of division of labour).

In sum, national integration is the process whereby people olparticular nation are linked together by a force--be that value or function- - so that resources are made available or accessibleto all the people, regardless of their status in the social hierachy. It is a constellation of social values, norms, social orgarisations and institutions. It is a condition, a state of affair to b achieved by the process of unification.

No siciety can be completely homogeneous in nature. Its parts and components are never similiar. In other words, a heterogeneous party make up the society. A process called integration is neded to bind them together. The process is a inter-group and nter-ethnic activity. 


\section{Statement of the Problem:}

Naturally, Nepal known as the abode of tranquility and serenity situated at the southern foothills of the snow-tipped mountains is wedged between India in South and China in North. Because of its undulated terrain spreading toward the South from the Himalayas, it has housed several zones ecologically different from each other and people culturally heterogeneous and ethnically diversified. In the ocean of diversification lies the dearth of resources, where one grour commands more of it than others resulting in an unequal distribution of power, prestige and wealth, consequently, one group suppresses the other for the sake of controlling these resources. Thus there are always conflicts and tensions in the society. Because the group is enjoying the privilege at the cost of others. The dissatisfaction of the under-privileged group has been heightened by many factors (1) the general awareress brought about by education among the people, (2) mobility due to regular and systematic development of transportation system, and (3) incidence of ethnic violence, war and crisis in \$outh Asian countries, where a number of ethnic wars have been taking place simultaneously for the identity of their ownethnic groups. This situation has further been aggravated by nternational incidence on ethnic problems. The above factorcoupled with effective mass communication has played an mportant role in stimulating ethnic crisis in the region. Because of these circumstances happening at the global level, Nephl has not remained unaffected in this regard as it is a country of heterogeneous ethnic group of individuals.

In order to find out the ways of new stengthening in the country it is necessary to understand to meaning of integration as perceived by the people both at he micro-level as well as macro-level and document the processes of national integration prevailing in the country. Thi addresses the following questions.
1. What is the socio-historical situation at which national integration process has been taking place in Nepal especially after the unification campaign initiated by Prithvi Narayan Shah ?

2. How is national integration perceived by Nepali people? And what are its political, social, economic and psychological dimensions?

3. What kind of problems are related to national integration and how can we create a conflict free situation in Nepal?

4. What is a Nepali culture around which heterogeneous groups of people can be integrated into a single whole Nepali culture?

5. How can we assimilate them into a wholeness both normatively (culture, values and norms) and functionally (interdependence)?

\section{Methods}

\section{Sources of Information:}

Primarily, data and information used in the study were collected from three different sources :

(i) Key informants at the micro level,

(ii) Individual respondents at two different villages representing Terai and Hill regions, and

(iii) Case studies of two internal organizations (Nepal Langhali Sangh of the Magars and Tamu Baudha Sewa Samiti of the Gurungs).

\section{Findings:}

A. Socio - historical context of Integration in Nepal

The territorial unification of Nepal had started some two hundred years ago at the time King Prithvi Narayan Shah, 
was the ruling monarch of the mini-kingdom of Gorkha. He conquered and unified various small scattered mini-kingdoms into one big kingdom now called the kingdom of Nepal. His greatness lies in the fact that even after conquering all these kingdoms, he never named the new country after his home country, Gorkha. Rather, he chose to name it Nepal and he made the valley of Kathmandu as the capital city of his new kingdom. His quotation on Nepal such as "the Garden of four varnas and thirty six castes" was his pious and far-sighted intention to keep all the people within the umbrella of larger Nepali nation-state.

It is said that Nepali culture is not an unique culture. Rather, it is the mixture or blending of Arya and Hindu cultures. Because of the fear of Muslim invasion even in Nepal, the different cultures got united or acculturated in Nepal and emanated as Nepali culture. This culture is the conglomeration of mountainous, Himali, Hilly and Terai cultures.

The periodic war with the British in India had sown a seed of patriotism in Nepali people to feel emotionally attached with Nepal and Nepali culture. The Rana regime, despite its tight control over the rule of Nepali people to keep them away from modernization, has been able to maintain the feeling of national integrity on Nepali people. The recruitment of Nepali people, especially from hill region of Nepal, to the Gurkha army in India and the Great Britain has also instilled in these people the feeling of "Nepal is our country and we are Nepali".

As a result, the movement of Jayatom Sanskritam initiated by a major party did bring out some programs for Nepali people to eradicate untouchability, eating in a place by the people of all caste-groupings, ploughing the land by the Brahmines, etc.

The psychological feeling "country is the common shelter for survival and co-existence" has led the Nepali people to work together in harmony and maintain unity in diversity in
the country.
Ths notion of "one nation and one nationality" has also equally penetrated deep into minds and souls of Nepali people which in turn has helped revive the already diminisning feeling of national integration in Nepal.

Nepali language as the national language and Hindu religion as the state religion have been adopted, to a great extent towards the integration of various societies into a whole society, called Nepali society. However the higways and airservices, the establishment of communication networks, and Nepalization on school curriculum have no less been important in the integration of its mutifarious culture into a one whole culture called Nepali culture. The division of the whole country into five different development regions and fourteen zones has helped integtate the people of different ecological regions as well as cultures into a single culture, national life culture of Nepal.

Last but not the least, the feeling that Nepal is a one nation and Nepali a one Jati, conglomeration of various varnas, castes (occupational group and cultures) has prevailed in our society for quite sometime. As long as this feeling persists in the hearts, minds and souls of Nepali people, the feeling of nationalism, and the strong desire to achieve the goal of national integration will always be in Nepali people, culture and then society. Our observation suggests to the fact that national integration is the Toyality of Nepali people to the nation, where people of different social characteristics can live together in harmony with a stong feeling of "togetherness" and solidarity. In it, they do develop the feeling of "oneness" and yet maintain their own cultural identity among various caste, language, religion and ethnic groupings. This is a condition, where they develop the feeling of brotherhood among various caste groupings.

National integration is the emotional unity of different enthnic groups, irrespective of religion, language, dress, place of residence, communities, etc. It is also the condition where the 
feeling of "security" prevails among them and extends mutual respect to each other's language, culture, religion, tradition and way of life and has rendered equal status in the society. Some key-informants even suggested the point that the national integration in Nepal implies the rejuvination of the notion of "Sabai Jatko Phulbari" and strenghthen this idea in the country.

\section{Political Dimension}

Politically, national integration is the condition of sharing power by people of different strata at the state affairs, where the state attempts to create a congenial atmosphere in order to secure people's genuine participation and their involvement voluntarily and spontaneously. People from different walks of life have their fair representation at the House where decision that affects the people are made jointly; parliamentary debates are carried out in a democratic manner; voices of minority are heard and the minority is given due respect so as to secure their full participation in the state affairs and policies are formulated to məet their demends, interests and needs. Policies are formulated to secure the participation of the depressed and downtrodden segment of the society in administration, civil service, army and police so that people's significant participation can be secured to mobilize national resources wisely forpeople'sbenefits in the country. The state should provide a forum where people of different ideological backgrounds can be accomodated in the process of decision making activities through mutual interaction and sharing of experiences on a regular basis. It was also suggested that the state should have a uniform system to provide opportunities to the people, and recruit people in the state system in such a way that the people from backward caste and ethnic groups can also enjoy the benefits of the state-run welfare programs

\section{Social Dimension}

Nepal is a mosaic of different caste and ethnic groupings scattered all over the country where cultural differences that prevail widely are primarily emanated of Hindu caste hierarchy adopted in the country. Their cultural differences can be minimized when their functional interdependency can be enhanced in the social system. This can be accomplished only upon the implementation and coordination of relationships among the people of different social backgrounds such as caste, religion, language, ethnic group, occupation, class, etc. and this coordination should be based on the principles of equality and non-descriminated policy, practice and behaviours. In a straight sense, there should be no descrimination against any individual on the basis of caste, sex, religion, ethnic groups, etc. The untouchability that is deeply rooted in Nepali society be eradicated socially. Its elimination by legal provision has been proved quite ineffective and inefficient in our culture and identity of all caste, ethnic grpups and religion should be maintained as charted out in the Muluki Ain of the country. In this way only harmony among people can be brought out and uniformity accomplished. In order to achieve all these points mentioned above, it is necessary to create an environment of judiciary equity where everybody will be equal to law.

\section{Economic Dimension}

The distribution of wealth and income is one indicator of measuring economic equality in the country. The indicator such as minimum basic income (MBI) indicates that 42.5 percent of the total population is below poverty line. Without eradicating this poverty, it is difficult to raise the living standard of the people in the country. There still lacks the coordinated plan to use the local resources, skills and sources. And people have not been able to tap the opportunities that are available around them due to reasons such as ignorance, lack of skills, primitive technology, etc. The specialized skills of the terai people, coupled with hard work and bravity and enterprising capability of the mountain residents should be merged skillfully to bring in economic integration in the country so that a self-reliant development can be achieved to distribute benefits and fruits of develoment 
to people - regardless of their economic and social status. A provision of uniform economic conditions and opportunities should be made available and a congenial environment should be created so as to have access to these opportunities on the basis of achieved qualities such as educational qualifications, skills, including, backwardness and remoteness.

\section{Psychological Dimension}

National integration, from phychological perspective, is the feeling of unity developed in people and their emotional attachment to nation. In fact, it is the feeling of people, who feel and develop the sense of unity and botherhood without any interference and imposition from outside. This feeling is strengthened by the people especially at the time of crisis, when sovereignty of a nation is endangered by external influence or cultural or political invasion. At this time, we need to develop a feeling of "we are one". This feeling can not be raised without any massive program geared to enhance the feeling of nationalism.

\section{Problems of Integration as perceived by respondents in Mepal}

The authors wanted to know the areas which have potential problems as perceived by them. It was our observation that majority of their opinions were basically zeroed on the questions of caste. religion, language and tradition. Some of the important problems reported by them are described below in a nutshell.

a. Underrepresentation: The main problem lying before us is that their is no representation in army, civil service, police and other semi-government sectors. It is said that Nepal is a multi-ethnic country but it does not have a multi-ethnic army. Ecologically, there is no representation from Terai region in the army. Those who are at the Royal Army are at constable level only and virtually there are no officers from these regions. Similarly, there are many caste groupings who have not had an access to the Royal Army.
The similar situation prevails in police too. However, a slightly improved situation can be seen in civil servico. Thus there is a great under-representation of many ethnic groups in these areas.

B. Descrimination Against Caste: The biggest and most serious problem faced by the nation is the question of untouchability deeply rooted in our society from the time immemorial. Among the caste grouping, the touchable or higher caste people are more privileged than the touchable ones. It was reported that the lower caste people who have been exploited by higher caste people is the main causes of social problems in Nepal.

c. Monopoly of Nepali Language and Hindu Religion: The philosophy of "one language, one country" has posed a serious threat to the survival of other languages spoken in various parts of the country.

d. The high proportion of illiteracy : The extent of poverty, difficulty of transportation and unreliability of communication have exacerbeated the problem of exploitation in the country, mainly the supression of lower caste and class groups by the privileged ones. Because of these constraints, the extent of exploitation and the pocket of poverty has distributed all country.

e. International domination and ideology have also been the important variable that have played an important role in the integration of the country.

Some of the areas suggested by key-informants to reduce the problems related to ethnicity, language, caste, religion, etc. are as follows:

a. Balance regional development : Economic prosperity of different ecological regions could solve the majority of the problems faced by the country especially the problems of exploitation through the utilization of local resources, skill and 
manpoweî and distribution of national resources wisely and proportionately.

b. The harmony between religions could minimize the discrimination caused by the domination of one religion by the other.

c. Because of Nepali language as a national language, other languages spoken by minorities as their mother tongues have been paid either no attention or least attention and thus totally overlooked by the majority. These languages can't be overlooked because they are also the national languages spoken by other segments of Nepali people All the languages should be equally treated even though Nepali is the official language adopted by the state as a national language.

d. Geographical constrains has played a prominent role to create an inequality among the people as far the distribution of resources are concerned in the country. The priority should be accorded to these backward tribes and downtrodden castes so that their fate, living standard can be raised without bringing any structural changes in status quo. The process of distribution could be further expedited by the application of decentralization principles and not the centralized principles.

e. The notion of, "one language, one religion, one culture" has deaccelerated the process of integration in Nepal due to its supression of other culture and languages, religion, etc. This notion should be removed from the mind of decision makers and policy maker in order to strengthen the nation of Unity in Diversity in Nepal as it is a fertile garden for all.

f. The principle of equality should be practiced to ensure an equal and active participation of the people to achieve the goal of reaching the beneficiaries.

\section{Cireation of a Conflict-free Situatien}

As has been reported else where in the paper that the conflict and tension have arisen very recently in Nepal and are the functions of domination of one language, religion and culture by another. Their exploitation and suppression have prevailed in the society to the extent that it has reached the boiling point after which it may take different course of action. Not only the domination of one caste by another but also the rapid acceleration of modernization process has caused some inevitable conflict and tension in the society The situation of conflict and tension can be uprooted by (i) equal treatment of all caste, language, ethnic groups, and religion, (ii) developing self-confidence, mutual trust, good will, and uniforming of Tapai (the use of Timi should be confined in family affairs, only), eliminating ego-feeling of higher caste people and upgrading inferior complexity of down-trodden people. And it was also suggested that some kind of conscious struggle should be carried out in order to raise awareness of people so that they can live in harmony regardless of caste, sex, languages, religion, etc. Also, it was observed that people should be brought to gether not by compulsion but by persuation and voluntarily. For that sake, the informants were asked about the mechanism of solving the conflict and tension in the society. The responses as recorded by the author are presented below:

a. The establishment of a fully democratic political system, where the minority should not be major beneficiary of the plans and programs. The target should always be the majority of the people from the middle and lower class, who are the silent majority of any society.

b. The formulation of a long term plans and programs should be developed right from the grassroot level so as to avoid the gap between the rich and the poor and to ensure a wider participation of people from all social backgrounds from the very beginning of a planning procedure. 
c. The establishment of a democratically constructed constitution and its strengthening by the people through political awareness program and continuously conscious struggle.

d. The constitutional restriction of communally motivatedethnic organizations should be brought into effect. However they should not be restricted if they would like to preserve and upgrade their culture and tradition. Once they go beyond this boundary, they should be bound to closure.

- A congenial environment should be created where people can develop good-faith, good will and mutuality. For any problem, party should be given an opportunity to tackle it promptly.

f. Massive awareness program should be carried out for people on minimizing the emergence of ethnic problems. And the principle of "get educated and get organized" should be applied to accomplish the mission.

g. A national policy and guidelines should be developed to explain the people the role of sovereignty, religious torture, class coordination, exploitation-free society, raising the living standard of the people below poverty line, etc.

h. The notion of "one religion, language and culture" should be abolished by providing equal status to all those concerned and emphasizing decentralized programming with a balanced regional development.

i. The coalition of crown, congress and leftist could be made a strong force of accelerating national integration process in Neoal by preventing conflict and tension both at local as well as national levels and allowing to grow more domocratic forces.

\section{Equality and Homogeneity:}

The melting point as regard the process of integration of different culture into one, it appears to be easy to say theoretically but is difficult to materialize it practically. Points raised here appears to be politically acceptable but difficult to implement socially. And some of the important points as perceived by our key-informants are briefly summarized below :

a. Some key-informants suggested that religion is an effective formula that binds up the whole nation into one single nation. Hindu Mation. The notion of one-language, one religion and a Hindu nation should be continued to bring the whole Nepali society into a homogeneous one in future. However majority of the respondents informed that the government should not favour a particular religion due to existence of other religions such as Buddism, Christianity and Muslims in the country.

b. The equality of opportunity should be provided to all people regardless of the caste, sex, ethnic group, language, religion, class, occupation, etc.

c. Provision should be made to allow mother tongue and other languages to be included in the curriculum upto high school level. This will be a good incentive to the speaker of other mother tongues.

d. Recognize Nepali as an official language but provide equal status to other mother tongues too by providing equitable representation in all institutions such as Royal Nepal Academy, Nepal TV, educational institutions, Radio Nepal etc.

e. A coordinating body should be established at the eentral level in order to coordinate various ethnic organizations dedicated to upgrade and improve the traditional norms and values of that particular ethnic groups and caste.

f. Parliamentary democracy is the fundamental force of unity that sustain the process of integration in the country. In the absence of democracy, the integration of the nation, Nepal, is not possible at all in Nepal, 
g. Allow political participation of the people according to their proportion of the total caste population in the national house.

h. Allow and encourage inter-caste, inter-communal marriage especially between the terai people and hill people to accelerate the process of acculturation in Nepal.

\section{Envision of a Nepali Culture: A Vital Necessity for Integration :}

Nepali culture and national life culture have been used here in this paper interchangeably. They are considered one and the same thing. Nepali culture reflects the Nepali thinking, doing, art, tradition and customs. In other words, it implies. both material as well as non-material culture. So Nepali culture is considered to be the pillar of national integration in Nepal. where diversed culture and ethnic groups make up of the whole nation, a Nepali. (i) People's perception (ii) Constitutional Provision, (iii) National norms and values.

Nepali culture is a mixed culture, where conglomeration of various national cultures have taken place to make a single culture called Nepali culture representing all three ecological cultures-Himali, Hill and Terai. It is an unity in diversity, which is an uniqueness of Nepal, where over 40 dialects are spoken and over five dozen ethnic groups people in an area of $1,46,000$ square kilometers live and support livelihood. It is a SANGAM of all cultures (tibet-mongloid, mixed and Indo-Aryan), traditions, customs, dresses, arts, .. eic, where they have developed their own cultural network for communication in the country. It is the nature of the Nepali culture, where the followers of several religions (Hindu, Buddhism, Muslim, Christian, Sikh, Jain, etc.) live together in harmony. And as such no evidences of religious riots and war have been recorded to bave occured in the country. Thus Nepali culture is an unique example of a religious harmony in Nepal.
Nepal is an abode of a multi ethnic, multi-lingual and multi-cultural groups of people, who have lived here for centuries and developed their own belief, customs and tradition.

Their conglomeration, blending and acculturation is popularly known by the name of Nepali culture. In other words, the culture of entire ethnic groups is the name of Nepali culture which is what is called Nepal's national life culture. Reciprocality, feeling of nationalism, respect to each others; recognition of constitutional monarchy as a source of unifying force, functional interdependence of different caste groupings, religious tolerance and harmony, ascriptive status, Nepali law, indigeneous way of hospitality by offering "Namaste", dresses of Nepali people, etc.

Politically, the pillars of national integration process has been provided by the constitution of the kingdom of Nepal (1990) which is the fundamental law of the nation. Its primary goal is to provide social, economic and political justice to the people of the kingdom of Nepal. In order to achieve these goals, the constitution provides the means of "adult franchise, parliamentary form of government, constitutional monarchy and multi party system".

The Constitution (1990) explaining the term "nation" explicity in the article 2 of the Part I states.

"The people of Nepal being united by bond of common aspirations and faith in the independence and integrity of the Nation, irrespective of religion, race, caste or tribe, colletively constitute the Nation".

The constitution has guaranteed the fundamental rights of the people in Nepal. These rights to equality, freedom, press and publication, information, and religion and cultural and educational rights. Thus the basic norms of the nation has been the democratic practices to be adopted by the state to maintain 
law and order in the country and provide basic human rights and welfare to the people of Nepal.

Last but not the least, the Constitution (1990:17) asserts "His Majesty is the symbol of the Nepalese nation and the unity of the Nepalese people... His Majesty is to nourish and protect Nepal".

\section{Emergence of Ethnic Organizations}

The political awareness of Nepali people is reflected in the formation of new ethnic group organizations, that have grown like anything during the last one and a half decades especially after the holding of referendum in Nepal in 1980. Since then more than two dozen ethnic organizations have been reported to have been established mostly by people of caste groups other than Brahmin and Kshetry. Some are purely based to promote and preserve their cultural heritage, whereas other are primarily organization to advance the communal feeling in the country. The former types of organizations are complement to national integration, whereas the latter are dangerous to the stability of the country: the emergence of these organizations has caused many people raise their eye-brow as far as national integrity is concerned. Here, the researcher has attempted to collect some information about merits and demerits of these organization, their threat to national integrity and means and ways to encougrage / discourage them in the present context.

It was reported to us that the formation of ethnic group organization raises the ethnic consciousness but their cast tell us about their rights (and less likely about their duties) and develops the feeling that their society should be developed. It will be helpfui and positive for the particular caste groups provided they are free from politicization and have no support from foreign powers. However, some informants suggested that they are dangerous to the integration of the country as they always divide the ethnic groups, politicize them and are communally oriented to achieve their goal. Some even argue that they are ethnocentric, too.

To the response of our question, "are they dangerous to national integration ?" informants suggested that it is dangerous and threatening because they are always communally oriented in their goals and bring the feeling of communalism and regionalism. If allowed to grow, it will be like the cases of Sri Lanka and India. It will be positive if it is established on the spirit of "Garden of all".

To the question on "Ways to eliminate them", it was reported that only full-fledged democracy, multi-party and strong constitution could put ban on communal slogan and publicity, communal feelings, etc. The party could help neutralize this feeling. Some opined that ethnic organizations should be discouraged as party can help voice their concerns and grievances at the parliament. But parliament is no substitute for non-governmental organizations and private volunteer organizations in any country.

\section{Conclusion and Discussion}

Some of the problems that our nation has faced are briefly summarized below.

(1) Many ethnic organizations have emerged over the last decades these organizations are primarily based on the principle of casteism and are intended to create communal conflict and tensions. Which are branded as communal organizations. The emergence of such organizations is very unfortunate to any country for its solidarity, integration, stability and survival specifically to a country like Nepal. It is estimated that there are presently as many as fifteen different ethnic organizations in Nepal. Some have the purpose of preserving their culture and upgrade their present lingual and ethnic status where as others are purely formed on communal basis so as to raise their 
âwareness to have more access to the available resources.

(2) The declaration of Nepal as a Hindu state has been considered by the followers of other religions such as Buddism, Christanity and Muslim, etc. as unilateral step to suppress and dominate religious freedom enjoyed by them for centuries. It is believed that they take this step as a way to alienate other religions from the mainstream of the nation.

(3) Ethnic groups other than those speaking Nepali as a mother tongue claim that their proporition has been misreported in the official statistics of Nepal where 584 percent population are reported to be speaking Nepali. Their main charge is that the proporation of population speaking Nepali is not that high as the above data are over- - reported.

(4) The social inequality created by under-representation of different caste people in army, civil service and police and disproportionate representation in the legislative body and judiciary has been seen as one of the major problems of national integration. Voices have been raised from different corners of the country including people from Terai on the ground that they have not been receiving equal treatment by the state,

(5) There are other problems, too For example the rule of the country by those who speak Nepali language as a mother tongue and follower of Hinduism, treatment of the residents of Terai region as second class citizen and free movement of Indians to Nepal without any restrictions are causing some serious problems of integration in Nepal.

Policy Recommendations:

1. At the Political Level

(a) A grand program should be designed to bring awarness bout the country, people, political system, constitution, etc for mass at the grassroot level so that the feeling of nationalism can be instilled in each and overy Nepali citizen of the country.

(b) The principle of "Share and care" should be adopted by the state at all levels so as to give people equal access to power and representation in legislature.

(c) The state also should make a provision for proportional representation of all the caste, ethnic groups and social class according to the proportion of their population at the national body. A special attention should be given to the backward tribes, socially depressed caste, and people from remote and inaccessible area.

(d) A quota system should be granted to the unprivileged people in civil, army and police services in the country.

E) Ethnic organizations should be encouraged to raise their voices and grievances regularly so that they can themselves be engaged with work of preserving their culture, language, tradition, etc. However care should be taken to avoid (even ban on restrictions on) organizations that are communally oriented in their goals.

2. At the Social Level

(a) Equal status should be given to all religions practiced, mother tongues spoken and cultural practices followed in the country. No language should be allowed to advance at the cost of other languages.

(b) The unique characteristics of Nepal is "Unity in diversity" and consequently the notion of "caste" should be preserved by maintaning in harmony and equality among all these caste groups. The intercaste mobility should be facilitated by allowing intcr - caste and even inter - communal marriages (marriage between a Terai man and Hill or mountainous women and vice versa) which 
will help mix the population with each other. Their offspring will be both socially as well as biologically adoptive to the heterogeneous condition of the country. This could be an one stage ahead towards the process of Nepalization in the country.

(c) The migration of hill people to the South has occurred in the country for some time even upto the extent of transmigration due to action of pull factors (economic opportunities) in Terai and push factors (hardships, natural calamities etc). in the hills and mountains. The continuation of the trend may cause similar problems by people in hills and mountains, even in Terai. This is just one way of human traffic among three ecological zones. This trend needs to be reversed back by developing pilgrimages tourisms, industries and uses of water resources, establishment of universities and technical institutes in the hills and mountains so that two-way traffic of people take place from these ecological zones. This will allow blending of people, cultures, customs, etc and save the fertile land of Terai from heavy pressures on agricultural land.

(d) The constitution laws and texts books should be published in other national languages.

\section{At the Economic Level}

(a) The living standard of the people who are below absolute poverty line should be raised by raising their percapita income and providing productive employment opportunities to them.

(b) The programs such as income generation activities providing opportunity etc should be developed so as to eradicate poverty, both absolute as well as relative, from the society. (c) The gap between the rich and the poor, inequitable distribution of resources among these ecological zones should be removed by allowing balanced regional development as well as providing equal access to the people regardless of their heterogeneous social backgrounds and status.

\section{At the Psychological Level}

The stateshould create a situation where people are free from exploitation, feel secured and have faith in the system designed for them and create an environment where people can trust each other and reciprocality can prevail in the society.

5. In order to achieve all these points mentioned above, it is necessary for the state (government) to develop a broad and comprehensive plan covering all aspects of national integration in the country. It should be both long as well as short-term in nature, specifically focussing on the areas which include;

( i) Provision of research on all mother tongues by the Royal Academy for their preservation and promotion

(ii) News and cultural programs of all mother tongues from Radio and TV.

(iii) Constitution Acts and Laws should be written in all languages,

(iv) Use of major languages in the court/legislative and offices

(v) Inclusion of mother tongues as an optional language,

(vi) Quota system of opportunities to all ethnic groups,

(vii) Equality in political participation by all caste and class, 
(viii) Exact record of languages, castes and their distribution,

( ix) Making awareness programs across the country.

Lastly, the feeling of Nepalism can not be attained simply by wearing Nepali Daura and Surwal and a Cap. Nor can it be attained just by having a state religion and national language in the country. Nepal is the country of heterogeneous groups of people, where unity prevails in diversity. The mandatory use of "one language, one nation ......" is a biased policy which can't blend the traditional and cultural difference of the people. And a condition of mutual trust, hate and love can't be attained until the total culture of Nepali people can be amal-gamated into one called the national life culture of Nepal. We believe that efforts should be geared toward that direction.

\section{References}

Angell Robert C., 1941. The Integration of American Societies, New York : New Magraw Hill

Angell Robert C., 1951. The Moral/ntegration of American Cities. The American Journal Sociology, Vol. Lvii No. 1 in two parts, Part 2

Ghurye, G. S., 1968. Social Tension in India. Bombay, Popular Prakashan

D'Souza, V. S., 1977. Inequality and Social Integration in an Industrial Community. Simla, Indian Institute of Advance Study.

Etzion, Amitai, 1965. Political Unification, New York Holt, Rinhart C Winston (As quoted in S. L. Doshi, Process of Tribal Unification and integration Concept Publishing Company, Delhi 1968).

Gaige, F. H., 1965. Regionalism and National Unity in Nepal, Vikas Publishing House Pvt.
Gurung, Harka B., 1980. Socio economic Dimension of National Integration: a paper Presented at the Seminar on political Dev. and Social Change in Nepal.

Gurung, Harka B., 1980. Social Dimensions of National Integration in Nepal. The Motherland July 14, Kathmandu.

Manandhar and Amatya, T. R. and P. K., 1989. Political Process and National Integration in Nepal. Rolamba, April - Jure.

OIsen, M. E., 1968. The Process of Social Integration. New Delhi : Oxford and IBH Publishing $\mathrm{Co}$.

Poudel, A. R., Nation Building in Nepal: A Case Study of the Past Revolution Period (1950-81) Unpublished Thesis Ph. D. Dept. of Political Sciences, T. U., Kirtipur.

Ranga Rao, AVP, 1989. Urbanization, Occupational Mobility and Social Integration. A Case Study of Scheduled Castes Deep. and Deep. Publication.

Sharma, P. R., 1987. Ethnicity and National Integration in Nepal: A statement of problem. Indian Journal of Nepalese Studies. July-Dec. No. 1 Vol. 1.

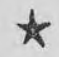

